\title{
Do Movimento de Securitização ao respeito pelo Princípio da não Discriminação - uma aproximação aos meios de tutela nacionais
}

From the securitization movement to the respect for the non-discrimination principle - an approach to the Portuguese legal remedies

\author{
INÊS FARINHA' \\ inesimoes@gmail.com \\ GALILEU - REVISTA DE DIREITO E ECONOMIA - e-ISSN 2184-1845 \\ Volume XX $\cdot 1^{\text {st }}$ January Janeiro - 30 ${ }^{\mathrm{TH}}$ June Junho $2019 \cdot \mathrm{pp}$. 99-121 \\ DOI: ??? \\ Submitted on February 13 $3^{\text {th }}, 2019 \cdot$ Accepted on May $28^{\text {th }}, 2019$ \\ Submetido em 13 de Fevereiro, 2019 . Aceite a 28 de Maio, 2019
}

RESUMO Orecente movimento securitário que tem assolado a Europa, aliado especialmente aos fluxos migratórios instigados essencialmente por conflitos armados, tem feito recrudescer a preocupação pela proteção dos direitos fundamentais dos (i)migrantes e dos que buscam proteção ou refúgio junto da comunidade internacional, nomeadamente quanto ao respeito pelo princípio da não discriminação racial e étnica, cor, nacionalidade, ascendência e território de origem. O clima de intolerância que vem marcando as sociedades hodiernas, fez com que os Estados, e, em particular o Estado Português, criassem nas suas legislações internas mecanismos de tutela a fim de debelar a disseminação de situações potenciadoras de discriminação racial. No caso português tal tutela encontra-se plasmada na lei, tanto de um ponto de vista administrativo quanto criminal.

PALAVRAS-CHAVE Securitização, migrações, não discriminação, direitos humanos, prática discriminatória, meios de tutela, contraordenação, crime.

ABSTRACT The most recent security movement which has spread throughout Europe, closely associated with the migration flows essentially triggered by armed conflicts, has been raising concern for the protection of human rights of both immigrant and refugees,

1 Doutoranda em Direito pela Universidade Autónoma de Lisboa. O presente trabalho foi elaborado no âmbito da unidade curricular do $1 .^{\circ}$ semestre do Curso de Doutoramento em Direito na Univ. Autónoma "Problemas Cerne da Ciência do Direito", subordinada ao tema "Análise crítica do processo de securitização das migrações e o desafio da regulação das migrações internacionais em conformidade com o respeito pelos Direitos Humanos", lecionada pela Professora Doutora Constança Urbano de Sousa. 
Do Movimento de Securitização ao respeito pelo Princípio da não Discriminação...

INÊS FARINHA

GALILEU · e-ISSN 2184-1845 - Volume XX - Issue Fascículo 1 · $1^{\text {st }}$ January Janeiro - 30 th June Junho 2019 · pp. 99-121

who seek a new life alongside the international community, namely regarding the respect for the non-discrimination principle on the grounds of racial, ethnic, color, nationality, ancestry and territory of origin. The climate of intolerance surrounding today's societies has lead the Governments, in particular the Portuguese Government, to create in their national legislations legal remedies to cease the widespread of potential racial discrimination events. In Portugal, those legal remedies are foreseen by law, both from administrative and criminal perspectives.

KEYWORDS Securitization, migration, non-discrimination, human rights, discriminatory practice, legal remedies, administrative offence, crime.

\section{Da atualidade do tema - notas introdutórias}

"Ninguém é igual a ninguém. Todo o ser humano é um estranho ímpar".

Carlos Drummond de Andrade

Vivemos a era das migrações no seu esplendor.

Desde tempos remotos, o homem sempre sentiu a necessidade de desbravar este admirável mundo novo ${ }^{2}$ transpondo fronteiras, essencialmente em busca de melhores condições de vida.

Nos últimos anos a Europa, à semelhança do resto do mundo, tem sido palco das maiores atrocidades humanas. Entre os anos de 2015 e 2016, a Europa viu chegar às suas portas um grande fluxo de migrantes e refugiados em busca de acolhimento, devido à instabilidade instigada, designadamente, pelo conflito armado nos seus países.

Hoje existem aproximadamente 65 milhões de pessoas deslocadas em todo o mundo, cerca de 40 milhões migram dentro dos seus próprios países em razão da guerra, pobreza ou perseguições políticas e cerca de 22,5 milhões são refugiadas. ${ }^{3}$

Na Europa, em particular desde a crise migratória de 2015, até ao início do ano de 2018, foram movimentadas, no âmbito dos dispositivos da recolocação e reinstalação mais de 33.00o pessoas, distribuídas por países como a Grécia, Itália e Turquia, sendo que o número não cessa de aumentar ${ }^{4}$. Pode mesmo afirmar-se que se tratará da maior crise humanitária desde o flagelo da II Guerra Mundial.

2 Fazendo aqui a alusão à obra de Aldous Huxley, "Admirável Mundo Novo".

3 Plataforma de Apoio aos Refugiados (Dados disponibilizados pelo ACNUR) [Consultado em: 16.01.2019].

Disponível em: http://www.refugiados.pt/a-crise-dos-refugiados/

4 Idem. 
Perante este cenário, urge trazer para o centro do debate, nomeadamente, do académico, (que aqui nos convoca redobrada atenção), o estudo de uma matéria que se encontra em permanente metamorfose.

É por isso mesmo que neste sentido nos propomos a traçar, o caminho nem sempre grato, de como em Portugal se tem vindo a lidar com a proteção dos direitos fundamentais dos migrantes, dando enfoque em especial, ao princípio da não discriminação, o qual, por via constitucional, se assume como lapidar e transversal ao problema.

Ao longo deste texto, que se pretende ensaístico, pretendemos centrar a nossa atenção, diríamos, redobrada, nos mecanismos que hoje em Portugal existem para proteger e dignificar o princípio da não discriminação no seio do fenómeno migratório.

Analisaremos o princípio da não discriminação, designadamente naquilo que são as características discriminatórias mais fortemente beliscadas, quando se trata de abordar a cena migratória - a origem racial e étnica, a cor de pele, a nacionalidade, a ascendência e o território de origem, trazendo à colação os instrumentos legais que estão ao dispor de qualquer cidadão que seja alvo de um tratamento desigual ou discriminatório.

Por outro lado, não nos poderíamos mostrar arredados da realidade que grassa paralelamente ao fenómeno migratório. O crescimento descontrolado de discursos de ódio, mormente nas redes e plataformas digitais ou o (re-)surgimento de fações políticas anti-imigração, têm propalado o retorno a ideários nacionalistas ${ }^{5}$, o que poderá antecipar uma vaga securitária extremada, esvaziando os cânones valorativos ínsitos ao espaço europeu.

Cientes de que esta se mostra uma questão cerne do direito, que urge ser desmontada e analisada pelo óculo académico, aceitamos o desafio de contribuir para uma (des-) construção da realidade que nos acerca - a da securitização - não deixando de por outro lado construir novas visões sobre a base que pretendemos que permaneça - a da não discriminação.

\section{A perceção da (i)migração - o impacto dos fluxos migratórios como uma pré-compreensão da securitização}

Uma questão recorrente que se coloca quando abordamos o tema dos movimentos migratórios, embora admitamos não ser a única, é o da perceção tida acerca desses movimentos e dos impactos gerados na opinião pública.

5 Recorde-se, a título exemplificativo, que o partido político AfD "Alternativa para a Alemanha", que se iniciara como um partido com pouca expressividade política, conseguiu entrar no Bundestag (Parlamento Alemão) a partir do momento em que o seu leit motiv passou a ser o tema das migrações. No centro do seu discurso político estão, inter alia, a onda de críticas tecidas "à política de porta aberta" da Chanceler Angela Merkel. 
Na verdade, uma maior ou menor perceção que possa ser tida, conduz posteriormente à monitorização de outros fenómenos, de entre os quais, a perspetivação da questão migratória pelas sociedades, catalisador de eventuais pré-conceitos potenciadores de comportamentos discriminatórios.

De acordo com European Social Survey, em 2002 Portugal posicionava-se, juntamente com países como a França ou o Reino Unido, como sendo exemplo de onde decorre a perceção de que o número de imigrantes é mais elevado do que aquilo que efetivamente é. Tal tendência manteve-se, ou melhor, agravou-se mesmo, volvidos 12 anos. Em 2014, o hiato entre a perceção e a realidade ganhou mais expressão, pois se em 2002 a distância era de 15 pontos percentuais, em 2014 subiu para 17 pontos percentuais. ${ }^{6}$

Em face dos dados demonstrados, descortinar-se-á a importância que pode ser atribuída aos imigrantes no contexto nacional, face aos demais residentes.

Por referência ao ano de 2017, a importância relativa dos imigrantes em Portugal no total de residentes era apenas de $3,9 \%$, vindo a assistir-se a um decréscimo da população estrangeira residente no país. ${ }^{7}$

Ainda assim, pese embora os resultados sobre as vantagens ou desvantagens da imigração não sejam lineares ${ }^{8}$, a verdade é que em Portugal, pelo menos nos últimos vinte anos (essencialmente entre 2002 e 2016) se tem verificado uma melhoria na perceção do impacto que a imigração gera, quando associada a um fator de melhoria tendencial da qualidade de vida das populações.

Não podemos ainda perder do horizonte de análise as consequências que os próprios fluxos migratórios representam. Essa constatação, determinará o cruzamento com a matéria do sentimento securitário que adiante exploraremos com mais detalhe, pelo que não é despicienda a verificação dos números apurados quanto aos fluxos de entrada de estrangeiros ${ }^{9}$.

6 OLIVEIRA REIS, Catarina (Coord.); GOMES, Natália - Indicadores de Integração de Imigrantes: Relatório Estatístico Anual. Lisboa: Alto Comissariado para as Migrações, 2018, p. 37.

7 Idem, p.41. Tal deve-se, segundo as autoras Catarina Reis Oliveira e Natália Gomes, devido ao saldo migratório negativo entre 2011 e 2016, ou seja, ao maior número de saídas do que de entradas. O saldo migratório negativo deveu-se à crise económica e financeira que assolou o país, tendo induzido a um efeito conjugado do abrandamento dos fluxos de entrada no país e do incremento dos fluxos de saída, atingindo-se o pico da quebra de entradas em 2012 (com apenas 14.606 entradas de imigrantes permanentes) e o pico das saídas do país em 2013 (com 53.786 saídas de emigrantes permanentes).

8 Idem, p.39. Dos países onde se destaca uma perceção positiva acerca do impacto da imigração salientam-se a Suécia, Dinamarca ou Irlanda, contrastando, por outro lado com países como a Hungria ou a República Checa, onde essa perceção resulta negativa.

9 GIL, Ana Rita - Imigração e Direitos Humanos. Lisboa: Petrony, 2017, p. 35. Para esta autora, "Etimologicamente, estrangeiro provém da palavra latina extraneus, de extra, que significa fora. Designa portanto o indivíduo extraneus - que não é membro de uma determinada comunidade (...)". 
Reportando-nos a uma realidade mais próxima, nomeadamente aos últimos três anos, o regime de entrada de estrangeiros conheceu, designadamente, ao nível legislativo, alterações expressivas que obtiveram refrações significativas nos movimentos de entrada. $\mathrm{O}$ regime jurídico de entrada, permanência, saída e afastamento de estrangeiros do território nacional, abrigado na Lei n. ${ }^{0} 23 / 2007$, de 4 de julho ${ }^{10}$, tem vindo paulatinamente a albergar $^{11}$ estatutos de entrada diferenciados e cada vez mais próximos daquilo que vão sendo as necessidades de deslocação de pessoas de uns países para outros. Inter alia, poder-se-iam destacar as áreas da investigação científica ou as atividades profissionais, independentes ou dependentes que assumem um lugar de destaque nas últimas revisões legais.

Paralelamente há ainda que assinalar aquilo que pode ser chamada de "inversão da tendência" quanto aos fluxos de entrada no território nacional. É que se até 2016, a tendência tinha sido a de um maior fluxo de saída, devido nomeadamente aos efeitos arrasadores da crise económico-financeira sentida em Portugal, a partir daquele ano denota-se uma inflexão, o que se demonstrou pelo aumento dos vistos de residência atribuídos e também um aumento do número global de autorizações de residência, incrementando por sua vez o total de residentes estrangeiros. ${ }^{12}$

Há ainda a assinalar a partir daquele ano um acentuado aumento do número de pedidos de proteção internacional, quer quando se trate de concessão do estatuto de refugiado, quer quando se trate das autorizações de residência por razões humanitárias ou proteção subsidiária.

A título de exemplo, se no início da década, e especialmente até 2014, os números de pedidos de asilo não ultrapassavam as cinco centenas, esse número quintuplica em 2016, verificando-se em 2017 cerca de 1750 pedidos $^{13}$.

Relembremos ainda que a "crise dos refugiados", em especial desde a denominada crise do Verão de 2015 foram recolocadas cerca de 33.721 pessoas refugiadas, sendo que Portugal se disponibilizou para acolher 1.010 refugiados provindos da Turquia bem como de outros países terceiros.

10 A regulação legislativa neste particular, rectius, o da imigração conheceu estádios anteriores, assumindo especial relevância no período póstumo de adesão à União Europeia, que culminou em 1998, com a aprovação do Decreto-Lei n. ${ }^{\circ}$ 244/98, de 8 de agosto, procedendo nomeadamente à transposição de diretivas e à adaptação a alguns dos passos dados no sentido da definição de uma política comum de imigração.

11 A Lei n..$^{\circ}$ 23/2007, de 4 de julho, teve seis alterações desde a sua entrada em vigor: uma primeira em 2012, com a Lei n. ${ }^{0}$ 29/2012, de 9 de agosto, a segunda, com a Lei n. ${ }^{\circ}$ 56/2015, de 23 de junho, a terceira com a Lei n. ${ }^{\circ} 63 / 2015$, de 30 de junho, a quarta com a Lei n. ${ }^{\circ}$ 59/2017, de 31 de julho, a quinta com a Lei . $^{\circ}$ 102/2017, de 28 de agosto e, por fim, a sexta com a Lei n. ${ }^{\circ}$ 26/2018, de 5 de julho.

12 OLIVEIRA REIS, Catarina (Coord.); GOMES, Natália, Op. cit., p. 45.

13 Ibidem. 
De acordo com fontes oficiais ${ }^{14}$, em 2016 chegaram à Europa 363.401 pessoas. Em janeiro de 2017, 5.483 pessoas chegaram por mar (4.292 a Itália e 1.192 às ilhas gregas), sendo que a grande maioria eram nigerianos e eritreus, em fuga do Líbano e da Jordânia devido à guerra civil e à falta de bens de primeira necessidade.

\section{A onda securitária}

O pós segunda guerra mundial deixou um legado de destruição um pouco por toda a Europa Ocidental. Foi neste período que a Europa viu chegar ao seu seio uma vaga migratória, sobretudo intraeuropeia, que tinha como fim operar à sua reconstrução. ${ }^{15}$

Em meados da década de 1970 do século passado, a crise provocada pelo petróleo e a sua subida de preço levaram a uma retração na política de atração migratória que até então se tinha verificado. Emergem assim as primeiras ondas protecionistas desencadeando nas décadas seguintes os movimentos de restrição de direitos dos cidadãos não membros da União Europeia.

Já na década de 1990, começaram a surgir restrições ao exercício da livre circulação que evoluiu mais tarde para fortes controlos migratórios com a criação de "zonas tampão", o que marcou uma política migratória com uma tónica repressiva e que desaguaria mais tarde no segundo pilar erigido por Maastricht - a política de segurança e defesa. O que, com o Tratado de Lisboa ficaria consolidado.

Com a vaga migratória os últimos dez anos, a União Europeia criou um verdadeiro arsenal tanto civil quanto militarizado para combater o fenómeno chamado de "internacionalização das ameaças externas e externalização das ameaças internas"16.

Num permanente ir e vir de consensos quanto a estratégias e políticas de integração, verificou-se, diríamos, um endurecimento de medidas securitárias que imprimiu uma carga "nacionalista" e uma vaga do sentimento "anti-imigratório", levando a que alguns países tivessem mesmo construído muros ${ }^{17}$ para evitar a entrada de imigrantes.

14 IOM, UN MIGRATION - Mediterranean Update: Migration Flows Europe: Arrivals and Fatalities (31 January 2017). [Consultado em: 17 de Janeiro de 2019]. Disponivel em: https://www.iom.int/infographics/mediterranean-update-migration-flows-europe-arrivals-and-fatalities-31-january-2017

15 PADILLA, Beatriz; ORTIZ, Alejandra - Fluxos Migratórios em Portugal: Do Boom Migratório à desaceleração no contexto de crise. Balanços e desafios. In Revista Interdisciplinar da Mobilidade Humana. Brasília. ISSN 1980-8585 . N. ${ }^{\circ} 39, \mathrm{~A} . \mathrm{XX}, 2012$, p. 159-184, p. 160. Recorreu-se a programas de trabalhadores convidados ou guestworkers que incluíram os países da Europa do Sul e de outras regiões como a Turquia e o norte de África, nomeadamente Marrocos.

16 Estes conceitos são-nos trazidos no texto da autoria de Ana Paula Brandão. BRANDÃO, Ana Paula - O nexo interno-externo na narrativa securitária da União Europeia. In Janus.Net e-journal of International Relations. Lisboa. e-ISSN 1647-7251. V. 6, N. ${ }^{\circ}$ 1, 2015, p. 1-20.

17 A título de exemplo podem destacar-se os $175 \mathrm{~km}$ de fronteira "muralhada" entre a Hungria e a Sérvia. 
A juntar aos movimentos migratórios e à aparente pré-conceitualização do imigrante como, "o inimigo" ou o "terrorista", não se pode também olvidar a herança deixada por aqueles que foram os ataques terroristas dos últimos 20 anos. Nova Iorque, Londres ou Madrid, entre tantos outros, fizeram emergir novas conceções da política de segurança, qua tale, e redesenhar novos conceitos. E o que se seguiu não foi exatamente uma mudança para melhor.

Como bem aponta MANuel monteiro Guedes VAlente ${ }^{18}$ "as execuções levadas a cabo pelos jihadistas do Estado Islâmico são aptos a gerar a incerteza da insegurança em qualquer lugar e em qualquer minuto e promover a paneonomia emergente da teoria do perigo terrorista".

Assim, os horrores disseminados pela vaga dos sucessivos ataques, fizeram surtir uma ampla narrativa de "tolerância zero"19 ${ }^{19}$ uma verdadeira caça ao homem, elevando o valor da segurança como bandeira sacrossanta da integridade do Estado.

Em Portugal como nos refere aquele autor ${ }^{20}$, "a influência do fenómeno terrorista nas decisões político-criminais sobre as prioridades de intervenção e de investigação criminal, estão expressas nas leis de política criminal portuguesas conforme se pode ler nos fundamentos da Lei de Política Criminal para o biénio 2017-2019"21.

Ora, tudo isto, e arriscaríamos a dizer, mas muito para além disto, encontra-se o aparecimento de novas correntes político-partidárias, que, à boleia dos acontecimentos foram tomando terreno, dando poder àquilo que a vox populi vem aplaudindo.

Tradicionalmente enraizada nas fações mais radicais à direita, tais forças políticas vêm subindo o seu tom de intervenção elevando a securitização a níveis de verdadeiro desvirtuamento do Estado de Direito, tal como o conhecemos.

Itália, Alemanha, Espanha, Suécia, Hungria são apenas alguns exemplos onde tais forças político-partidárias estão em franca expansão, adotando um discurso nacionalista e xenófobo sob o leit motiv da imigração como o centro da ação política e de corrida eleitoral.

Dos múltiplos exemplos que aqui podiam ser coligidos, recorde-se a atitude do governo dinamarquês, que num recente acordo com o partido de extrema-direita "Partido do Povo Dinamarquês" (DPP, sigla oficial), decidiu enviar "imigrantes indesejados" para uma ilha

18 VALENTE, Manuel Monteiro Guedes - Direito Penal do Inimigo e o Terrorismo. 2.. ${ }^{a}$ ed. Coimbra: Almedina, 2017, p. 81.

19 Idem, pp. 86-87. A expressão faz parte como denota Manuel Guedes Valente de uma das três subespécies da tendência securitária, a par do "Movimento Lei e Ordem" e o "Estado Polícia".

20 RODRIGUES, Anabela Miranda - Política Criminal - Novos Desafios, Velhos Rumos. In Liber Discipulorum Jorge de Figueiredo Dias, apud VALENTE, Manuel, ob. cit., p. 91.

21 A Lei n. ${ }^{\circ}$ 96/2017, de 23 de agosto define os objetivos, prioridades e orientações de política criminal para o biénio de 2017-2019, em cumprimento da Lei n..$^{\circ}$ 17/2006, de 23 de maio, que aprova a Lei-Quadro da Política Criminal. 
remota, os quais tinham cometido crimes, mas não podiam voltar para os seus países de origem. ${ }^{22}$

O movimento securitário gera assim extremismos ideológicos e polvilha as correntes de pensamento dos governantes um pouco por toda a Europa. Para isto contribuem também muito as novas tecnologias, motor de difusão que se quer rápido e eficaz.

É neste cozinhado das correntes securitárias pós-modernas que emergem novas formas de disseminação de discursos de ódio, não sendo determinável a separação entre aquilo que é liberdade de expressão e ofensa à honra.

Donde, do que é possível constatar, sobretudo através das plataformas digitais, dando especialmente enfoque às redes sociais, o discurso de ódio ${ }^{23}$ (hate speech na fórmula anglo-saxónica) tornou-se um lugar comum, com recurso recorrente à estereotipização de pré-conceitos, à propalação de convicções radicais, a juízos de valor que não raras vezes fazem associações desenquadradas daquilo que a realidade por vezes falece em mostrar.

\section{Os instrumentos legislativos nacionais e supranacionais}

Face ao cenário que fomos traçando anteriormente, necessário é agora que se olhe a temática da não discriminação pelo óculo normativo-legal, tanto interna como externamente.

A um nivel supranacional, encontramos diversos instrumentos legais que são a chamada pedra angular onde a temática da não discriminação repousa.

A codificação de leis de caráter internacional, veio muscular a proteção dos direitos individuais, e erigir a valor universalmente reconhecido certos mínimos normativos, de tal modo que, como bem refere ANA RITA GIL "a arquitetura do direito internacional dos

22 Recordem-se a este título as palavras proferidas pela Ministra da Imigração dinamarquesa, Inger Stojberg na sua página oficial do Facebook: "Se é indesejado na sociedade dinamarquesa, não deve ser incómodo para os dinamarqueses. Os migrantes que são condenados por infrações penais, lei de armas, tráfico de drogas, entre outras, serão movidos para a ilha de Lindholm. Eles são indesejados na Dinamarca e vão sentir isso". A ilha de Lindholm abriga atualmente estábulos, laboratórios e crematórios de um centro de investigação de doenças contagiosas de animais. DIÁRIO DE NOTÍCIAS - Dinamarca quer isolar migrantes "indesejados" numa ilha. [Consultado em: 15 de Janeiro de 2019]. Disponível em: https://www.dn.pt/mundo/interior/dinamarca-quer-isolar-migrantes-indesejados-numa-ilha-10274361.html

23 De acordo com a Recomendação do Comité de Ministros do Conselho da Europa, "(...) the term "hate speech" shall be understood as covering all forms of expression which spread, incite, promote or justify racial hatred, xenophobia, anti-Semitism or other forms of hatred based on intolerance, including: intolerance expressed through aggressive nationalism and ethnocentrism, discrimination and hostility against minorities, migrants and people of immigrant origin". UNIÃO EUROPEIA - Conselho da Europa. Recomendação 97(20), de 30.10.1997. "Recommendation of the Committee of Ministers to Member States on "Hate Speech". [Consultado em: 18 de Janeiro de 2019]. Disponível em: https:// rm.coe.int/CoERMPublicCommonSearchServices/DisplayDCTMContent?documentId=0900001680505d5b 
direitos humanos é construída em torno da premissa de que todas as pessoas, em virtude da sua essência de humanidade, devem gozar de todos os direitos humanos (...)".24

Afinando todo este catálogo supranacional pelo mesmo diapasão, vejamos de que forma se acha positivado o princípio da não discriminação.

Primeiramente, há que reconhecer, que de um mero ponto de vista semântico, a expressão "não discriminação" pressupõe ou remete-nos para uma ideia de igualdade, equidade ou equiparação ${ }^{25}$. O que desde logo implica que, sendo os estrangeiros titulares de direitos fundamentais “(...) o conteúdo desse direito terá de ser à partida idêntico ao direito de que é titular um cidadão português a não ser que haja um fundamento bastante para o legislador estabelecer uma distinção" ${ }^{26}$

A par da legislação interna, é imperioso que radiografemos os variados postulados internacionais no sentido de que todos são erigidos sob a mesma égide: a da dignidade da pessoa humana.

A Declaração Universal dos Direitos Humanos (DUDH), a Carta das Nações Unidas ${ }^{27}$ ou o Pacto Internacional dos Direitos Civis e Políticos (PIDCP) consagram o princípio da não discriminação, essencialmente baseada na não distinção entre raça, sexo, língua ou religião, cultura, etnia, nacionalidade, entre muitas outras formas de discriminação.

Fruto essencialmente da devastação humana desencadeada pela Segunda Grande Guerra, a Carta das Nações Unidas ${ }^{28}$ assumiu-se como o grande primeiro referente jurídico-normativo, determinando como um dos seus objetivos a igualdade de todos os seres humanos no gozo de direitos em posição de igualdade. O seu artigo $1 .^{\circ}$ previa já que um dos objetivos das Nações Unidas é o de promover e estimular o respeito pelos direitos humanos pelas liberdades fundamentais de todos sem distinção da raça, sexo, língua ou religião.

A DUDH, nos seus artigos $1 .^{\circ}, 2^{\circ}$ e $7 .^{\circ}$, mais do que postular princípios universalmente válidos e reconhecidos pelos povos, veio dar relevo à relação existente entre o princípio da igualdade e o princípio da não discriminação.

24 GIL, Ana Rita - Imigração..., p. 182.

25 O que está em causa no princípio da igualdade é "a igualdade por se tratar de um ser humano e não por ser gordo ou magro, feio ou bonito, negro, branco ou pardo, pobre ou rico. Tratar os homens com igualdade é alocá-los no mesmo nível, ou seja, tratá-los como seres humanos". MOURA, Patrícia de - A Finalidade Do Princípio Da Igualdade: A Nivelação Social: Interpretação Dos Atos de Igualar. Porto Alegre: Sérgio António Fabris, 2005 , p. 23.

26 GIL, Ana Rita - Imigração..., p. 251.

27 Com o surgimento das Nações Unidas em 1945 e com a adoção da Carta de Direitos Fundamentais, erigiu-se a princípio supremo, a igualdade de todos os seres humanos no gozo pleno dos direitos humanos, estando consagrado no seu artigo $55^{\circ}$ que "com o fim de criar condições de estabilidade e bem-estar, necessárias às relações pacíficas e amistosas entre as Nações, baseadas no respeito do princípio da igualdade de direitos e da autodeterminação dos povos, as Nações Unidas promoverão o respeito universal e efetivo dos direitos do homem das liberdades fundamentais para todos, sem distinção de raça, sexo, língua ou religião".

28 A Carta das Nações Unidas, assinada em São Francisco, a 26 de Junho de 1945, entrou em vigor na ordem internacional a 24 de Outubro de 1945. 
O Pacto Internacional dos Direitos Civis e Políticos, no seu artigo $2 .^{\circ}, \mathrm{n} .^{\circ} 1$ refere na mesma linha a não discriminação por motivo de raça, cor, sexo, língua, religião, opinião política ou de qualquer outra natureza, origem nacional ou social, situação mas mais que tudo, este instrumento veio estabelecer os deveres do Estados de garantirem a não discriminação no gozo dos direitos aí previstos.

Sem prejuízo do peso histórico assumido por tais diplomas, é, contudo, a Convenção Internacional para a Eliminação de Todas As Formas De Discriminação Racial, adotada pela Assembleia Geral da ONU em Dezembro de 1965, que assume destaque, nomeadamente no que se refere à definição de discriminação racial, afirmando-se como uma antecâmara conceptual, avançando o conceito de "discriminação racial"29.

No que diz respeito à discriminação, no seu todo, foi sob o amparo das Nações Unidas que na década de sessenta do século passado, emergiram outros diplomas internacionais, dos quais cumpre destacar, o Pacto Internacional dos Direitos Económicos, Socias e Culturais (PIDESC), de 1966, a Convenção sobre a Eliminação dos todos os modos de discriminação contra as Mulheres de 1979, a Declaração sobre Eliminação de todas as formas de Discriminação, de 1963 e, em 1965, a Convenção internacional sobre a Eliminação de todos modos de discriminação em razão da raça.

No entorno europeu, o princípio da não discriminação está também positivado em múltiplos diplomas.

A Carta Europeia dos Direitos Fundamentais da União Europeia consagra no seu artigo $2 .^{\circ}$, n. $^{\circ} 1$ que é proibida a discriminação em razão, designadamente, do sexo, raça, cor ou origem étnica ou social, características genéticas, língua, religião ou convicções, opiniões políticas ou outras, pertença a uma minoria nacional, riqueza, nascimento, deficiência, idade ou orientação sexual".

Mas também a Convenção Europeia dos Direitos Humanos proíbe a discriminação no seu artigo $14{ }^{\circ}$. O gozo de quaisquer direitos previstos na Convenção deve ser assegurado sem discriminação em qualquer razão da raça, sexo, cor, língua, religião, opinião política ou nacionalidade, pertença a minoria, riqueza, nascimento ou qualquer outra condição.

Há ainda que olhar para o peso que as Diretivas assumem neste particular, em especial a Diretiva 2000/43/CE, de 29 de junho de 2000, conhecida como a Diretiva "Raça" que aplica o princípio da igualdade de tratamento entre pessoas, sem distinção da origem racial ou étnica.

29 De acordo com o artigo I da Convenção Internacional sobre a Eliminação de Todas as Formas de Discriminação, a expressão "discriminação racial" significa qualquer distinção, exclusão, restrição ou preferência fundadas na raça, cor, descendência ou origem nacional ou étnica que tenha por fim ou efeito anular ou comprometer o reconhecimento, o gozo ou o exercício, em igualdade de condições, dos direitos humanos e das liberdades fundamentais nos domínios político, económico, social, cultural ou em qualquer outro domínio da vida pública. 
Esta diretiva veio primacialmente estabelecer o princípio da igualdade de tratamento nos Estados-membros com o objetivo de instituir um quadro jurídico para o combate à discriminação baseada em motivos de origem racial ou étnica, albergando no seu âmbito tanto os setores público e privado, em diversas áreas, seja no acesso ao emprego ou a atividade profissional, como à proteção social, incluindo a segurança social, à educação ou prestação de serviços, incluindo a habitação.

\section{Os instrumentos legislativos internos constitucionais e infraconstitucionais}

Internamente o referente valorativo-normativo que encima a igualdade e não discriminação é o artigo $13 .{ }^{\circ}$ da Constituição da República Portuguesa ${ }^{30}$. Não sendo nosso ensejo escalpelizar aquilo que são as várias aceções e dimensões do princípio da igualdade, contudo o princípio da não discriminação, como nos ensinam GoMEs CANOTILHO E VITAL MOREIRA $^{31}$, constitui uma das dimensões constitutivas do princípio da igualdade ${ }^{32}$, em que não são legítimas quaisquer diferenciações de tratamento entre os cidadãos baseadas em categorias meramente subjetivas ou em razão dessas categorias.

Podemos afirmar que quanto à discriminação racial e étnica a Constituição de $1976^{33}$, à boleia dos textos normativos internacionais, veio elencar no seu texto, aqueles que são os fatores ou características protegidas, realçando-se, entre outras ${ }^{34}$ - sexo, língua, religião, convicções políticas ou ideológicas, instrução, situação económica, condição social ou orientação sexual - a ascendência, a raça, ou ainda o território de origem.

Não se olvide, porém, que o artigo $8 .^{\circ}$ merece neste contexto destaque uma vez que é este preceito que faz o enlace entre o direito interno e o direito internacional, abrindo a

30 Relembrando o teor do artigo $13 .^{\circ}, \mathrm{n} .{ }^{\circ} 2$ da CRP: "Ninguém pode ser privilegiado, beneficiado, prejudicado, privado de qualquer direito ou isento de qualquer dever em razão de ascendência, sexo, raça, língua, território de origem, religião, convicções políticas ou ideológicas, instrução, situação económica, condição social ou orientação sexual.

31 CANOTILHO, J.J. Gomes; MOREIRA, Vital - Constituição Anotada. Volume I, 4.. ${ }^{a}$ ed. rev. Coimbra: Coimbra Editora, 2007, p. 339.

32 Os autores referem também, a par desta, a proibição do arbítrio e a obrigação de diferenciação, como forma de compensar a desigualdade de oportunidades, ob. cit. p. 339.

33 A Constituição de 1976 ostenta algumas marcas de originalidade, desde logo por ter feito a receção formal da Declaração Universal dos Direitos Humanos enquanto critério de interpretação e integração das normas sobre direitos fundamentais. É por isso que o artigo $16 .^{\circ}, \mathrm{n} .^{\circ} 2$ da CRP estabelece que "os preceitos constitucionais e legais relativos aos direitos fundamentais devem ser interpretados de harmonia com a Declaração Universal dos Direitos do Homem", in MIRANDA, Jorge - Manual de Direito Constitucional. Tomo II. 3.. ${ }^{\text {a }}$ ed., reimpr. Coimbra: Coimbra Editora, 1996, p. 37 e ss.

34 As quais aqui não serão objeto de estudo, mas que assumem igualmente destaque no texto constitucional e, portanto, são merecedoras de um estudo paralelo. 
porta a que normas e princípios de direito internacional sejam parte integrante e constituinte do direito português.

De fora da previsão do artigo $13 .^{\circ}, \mathrm{n} \cdot .^{\circ}$ 2, estão duas outras características protegidas, a nacionalidade e a cor da pele. Não obstante, tal não significa que não estejam abrangidos pelo facho de proteção constitucional, designadamente no artigo $26 .^{\circ}, \mathrm{n} .^{\circ} 1$ da $\mathrm{CRP}$ que protege o direito à proteção legal contra quaisquer formas de discriminação.

O que quer dizer que, acompanhando o que proclamam GoMES CANOTILHO E VitAL MOREIRA $^{35}$, atentas as metamorfoses dos comportamentos sociais, das inúmeras fontes normativas, quer internas, quer externas, bem como pela emergência de novas vagas e tendências discriminatórias, era necessária a criação de um novo direito pessoal que abarcasse estas novas realidades. $\mathrm{O}$ artigo $26 .^{\circ}$ da CRP assume, portanto, uma dualidade própria, combinando a exigência de proteção e a prática de discriminação, que, cremos, complementa axiologicamente o consagrado no artigo $13 .^{\circ}$, n. ${ }^{\circ} 2$ da CRP.

Ao longo da Constituição vamos encontrando refrações do princípio da proibição da discriminação, por referência aos fatores elencados naquela norma constitucional.

Logo no artigo $15 .^{\circ}$ da CRP encontramos o que se pode chamar de cláusula geral de equiparação entre nacionais portugueses e estrangeiros ou apátridas. $\mathrm{O}$ caráter universalista ${ }^{36}$ que trespassa este artigo, encimado pelo valor da dignidade da pessoa humana, faz com que se estabeleça um critério basilar quando se trata de consagrar os direitos fundamentais de cidadãos estrangeiros - o de que é reconhecido a todos os estrangeiros, a par dos direitos, liberdades e garantias, os direitos económicos, sociais e culturais.

De facto, é precisamente essa a ratio legis imbuída no artigo $59 .^{\circ}$, devoto aos direitos dos trabalhadores, especialmente alicerçado na proibição de discriminação em razão da idade sexo, cidadania, raça, território de origem ou convicções políticas ou ideológicas, ou no também no artigo $74 .^{\circ}$, n. $^{\circ} 2$, al. j) $)^{37}$ no que concerne ao direito ao ensino.

Sem nos querermos embrenhar na análise jurídico-constitucional que o princípio da equiparação sempre merece, a própria Constituição estabelece também derrogações a tal princípio, designadamente no que tange a direitos políticos, o exercício de funções públicas

35 CANOTILHO, J.J. Gomes; MOREIRA, Vital - Constituição Anotada. Volume I, 4.. ${ }^{a}$ ed. rev. Coimbra: Coimbra Editora, 2007, nota de rodapé 31, pp. 469-470.

36 GIL, Ana Rita - Imigração...,p. 9, fala-nos da ideia de universalismo dos direitos que se encontra na génese do artigo $15^{\circ}$, e destarte no princípio da equiparação aí previsto, o qual encontra ainda respaldo no princípio do respeito pelos direitos humanos como princípio norteador das relações internacionais que deriva do artigo $7 .^{\circ}$ da CRP.

37 Refere este artigo o seguinte: "Na realização da política de ensino incumbe ao Estado: (...) j) Assegurar aos filhos dos imigrantes apoio adequado para a efetivação do direito ao ensino" 
sem caráter predominantemente técnico, e outros direitos reservados por lei a cidadãos portugueses (direitos de organização política e da comunidade).

Feita uma brevíssima incursão na lei fundamental passemos à aproximação daquilo que são, os meios de tutela previstos no ordenamento jurídico português, no que diz respeito à prevenção, proibição e combate à discriminação em razão da origem étnica e racial, cor, nacionalidade, ascendência e território de origem.

O nosso ensejo será essencialmente o de escalpelizar os dois meios de tutela previstos na ordem jurídica - a tutela administrativa e a tutela criminal, que têm encontrado no plano da aplicação da lei alguns constrangimentos que importa delimitar.

Por outro lado, uma análise pura das fontes não dispensa um enquadramento social da temática, dada a sensibilidade que o tema sempre acarreta, especialmente no quadro securitário que atravessamos, e que vai ser o mote para o nosso contributo crítico final.

\section{A. A tutela administrativa - A Lei n. ${ }^{\circ}$ 93/2017, de 23 de agosto}

Em 1 de setembro de 2017, entra em vigor a nova lei que visa a promoção da igualdade e a prevenção e o combate à discriminação de base racial e étnica em Portugal.

Com esta lei inaugurou-se um novo ciclo no que diz respeito ao combate à discriminação racial e étnica adaptando-se o regime jurídico nacional às orientações às políticas públicas nacional, europeia e internacional de forma a permitir um combate mais eficiente e efetivo ao fenómeno da discriminação.

Não obstante, o ordenamento jurídico português contemplava já desde finais da década de noventa do século passado, através da Lei n. ${ }^{\circ}$ 134/99, de 29 de agosto o regime jurídico que proibia a discriminação no exercício de direitos por motivos baseados na raça, cor, nacionalidade ou origem étnica.

Certo é que esta lei enfermava de variadas debilidades.

Em primeiro lugar, ao nível da tramitação processual, as responsabilidades processuais encontravam-se repartidas entre entidades diferentes ${ }^{38}$, o que contribuía para um excessivo retardamento do processo, fomentando um constante ir e vir que acabava por desencorajar o impulso processual por parte das vítimas, a fim de serem responsabilizados os autores de eventuais práticas discriminatórias.

Por outro lado, tal descrença alicerçava-se também na ausência de prazos para a realização da fase de instrução, em que não era acometido um limite temporal para cumprimento

38 Nos termos de tal lei, à Comissão para a Igualdade e Contra a Discriminação Racial competia acompanhar a aplicação da lei, designadamente aplicar as sanções que ali se achavam previstas, contudo, a fase instrutória, estava acometida a outras entidades, na sua maioria Inspeções-Gerais que procediam a toda a recolha de prova, finda a qual, devolviam o processo à CICDR para elaboração de relatório final. 
por parte das Inspeções-Gerais a quem estava atribuída a tarefa de investigar os factos, o que fazia com que muitos processos acabassem por prescrever ${ }^{39}$. Verificava-se igualmente que, embora muitos processos coubessem nas competências materiais das Inspeções-Gerais a que estavam acometidos, certas situações não se encontravam abrangidas por tais competências ${ }^{40}$, sendo inevitavelmente conclusos por ausência de entidade/inspeção-geral que procedesse à instrução.

Mais tarde, a Lei n. ${ }^{\circ}$ 18/2004, de 11 de maio, que transpôs para o ordem jurídica nacional a Diretiva 2000/43/CE, veio melhorar o quadro legal existente, na medida em que veio alargar o âmbito de aplicação da lei ${ }^{41}$. Mas não apenas, dado que, veio também permitir a intervenção das associações de defesa da não discriminação baseada na origem racial e étnica, nos processos jurisdicionais (artigo 5. ${ }^{\circ}$ da Lei n. ${ }^{\circ}$ 18/2004) ou ainda estabelecer regras quanto ao ónus da prova. Segundo este, incumbia a quem alegasse ter sofrido a prática discriminatória, o ónus de a provar, apresentando razões de facto suscetíveis de a indiciarem e quem alegadamente a tivesse praticado, sustentar que efetivamente as alegadas diferenças de tratamento não assentavam em nenhuma das práticas discriminatórias com base na raça, cor, nacionalidade ou origem étnica.

Contudo, verificava-se a persistência das mesmas debilidades da lei antecessora.

Ou seja, a lei de 2004 acabava por não prever uma alternativa quanto ao procedimento a ser seguido quando inexistisse uma Inspeção-Geral ou outra entidade sem competência para uma determinada situação fática, também acabava por não prever qualquer prazo para a conclusão da fase instrutória.

Em função da regra do ónus da prova e a dificuldade em reunir elementos da prática de um ato discriminatório e muitas vezes a ausência de resposta dos denunciantes a fim de esclarecer dúvidas relacionadas com a queixa explicam os números baixos, quer de queixas recebidas junto da Comissão para a Igualdade e Contra a Discriminação Racial, quer ainda a efetiva abertura de processos de contraordenação.

Daí que os números ofereçam este olhar clarividente da realidade então existente. Segundo dados do Observatório das Migrações ${ }^{42}$, no lapso temporal de treze anos - entre

39 De acordo com o previsto no Decreto-Lei n. ${ }^{\circ} 433 / 82$, de 27 de outubro, designadamente no artigo $27 .{ }^{\circ}$, os prazos de prescrição ali previstos repartem-se em três: 5 anos quando se trate de contraordenação a que seja aplicável uma coima de montante máximo igual ou superior a 49.879,79€; 3 anos quando seja aplicável coima de montante igual ou superior a 2.493,99€ e inferior a 49.879,79€; 1 ano, nos restantes casos.

40 Por exemplo pode-se apontar uma situação ocorrida em práticas discriminatórias ocorridas no seio de relações de vizinhança, que careciam de uma entidade que assumisse a competência para a fase instrutória.

41 Âmbito esse que com esta lei de 2004 se alargou, entre outras, à proteção social, educação, acesso e fornecimento de bens, incluindo a habitação.

42 OLIVEIRA REIS, Catarina (Coord.); GOMES, Natália - Monitorizar a Integração de Imigrantes em Portugal: relatório estatístico decenal. Lisboa : Alto Comissariado para as Migrações, 2014, p. 204. 
2005 e 2013, apenas foram recebidas na CICDR 615 queixas, mas apenas 194 deram origem a processos de contraordenação, cerca de $32 \%$, no total de queixas.

Traçado o panorama do fenómeno da discriminação racial e étnica, naquilo que foi a sua realidade até ao ano de 2014, a Lei n. ${ }^{\circ}$ 93/2017, de 23 de agosto veio tentar locupletar algumas pontas soltas que até então não tinham encontrado respaldo legal e, por outro lado, buscar respostas para o coro de críticas que se vinham levantando.

Desde logo, na senda do vasto manancial legislativo internacional ${ }^{43}$, esta lei veio abarcar uma série de novas competências - de que realçamos a nova competência de instrução de processos de contraordenação acometida ao Alto Comissariado para as Migrações (ACM, I.P.), veio (a) prever novos conceitos, como sejam o de discriminação por associação ou discriminação múltipla ou a inserção de duas novas características protegidas - a ascendência e o território de origem, (b) introduziu mecanismos de resolução alternativa de litígios, de que destacamos o mecanismo da mediação, (c) procedeu à alteração das regras do ónus da prova, presumindo-se a intenção discriminatória sempre que se verifique uma prática discriminatória, sem necessidade de prova dos critérios que a motivaram (artigo $14 .^{\circ}$ ) ou ainda (d) a faculdade de as associações ou organizações não-governamentais que acompanhem a temática da prevenção e combate à discriminação racial se poderem constituir como assistentes, e, destarte, intervir como parte nos processos jurisdicionais em defesa de direitos e interesses coletivos.

Na verdade, a introdução destes novos mecanismos, aliados à nova competência instrutória atribuída ao ACM, I.P., mas, mais importante, à previsão de prazos para a duração da fase de recolha de prova - prazo de 90 dias, prorrogável por um período máximo de 60 dias, em casos de fundamentada complexidade - fez do ano de 2017, um verdadeiro ponto de viragem no panorama da discriminação racial e étnica em Portugal.

Desta feita, os números falam por si. De acordo com dados do Relatório Anual da $\mathrm{CICDR}^{44}$, só no ano de 2017 foram recebidas 179 queixas, um aumento de cerca de $50 \%$, quando comparado com dados homólogos anteriores, sendo que a expectativa é que tal número continue a crescer. Se em 2013, das 60 queixas recebidas pela CICDR, apenas em 19 foi aberto processo de contraordenação, em 2017, do total de 179, 44 deram origem à abertura de processo de contraordenação.

43 Falamos aqui da Declaração Universal dos Direitos Humanos, do PIDCP, do PIDESC, da Convenção Internacional sobre a Eliminação de Todas as Formas de Discriminação, a Declaração sobre a Eliminação de Todas as Formas de Discriminação, Tratado da União Europeia ou ainda a Carta dos Direitos Fundamentais.

44 CICDR - Relatório Anual 2017: Igualdade e Não Discriminação em razão da Origem Racial e Étnica, Cor, Nacionalidade, Ascendência e Território de Origem. [Consultado em: 16 de Janeiro de 2019]. Disponível em: https://www.cicdr.pt/-/relatorio-anual-sobre-a-situacao-da-igualdade-e-nao-discriminacao-racial-e-etnica, p. 16. 
Contudo, no ano de 2018 uma nova subida se regista. Em termos comparativos com dados homólogos do ano anterior, foram recebidas 346 queixas, verificando-se um aumento de cerca de $93,3 \%$, sendo que desse total foram abertos 53 processos de contraordenação, correspondendo a cerca de $16,2 \%$ do total de queixas rececionadas.

Não obstante, apesar do novo mecanismo referente ao ónus da prova, o qual veio precisamente facilitar a abertura de processos de contraordenação, a verdade é que o baixo número de processos se deveu, em parte, à ausência de respostas a pedidos de informação adicional aos denunciantes numa fase prévia à abertura da instrução, segundo as razões apontadas naquele Relatório Anual.

Outras debilidades podem ser apontadas a esta lei. Atentemos em algumas.

Desde logo, se percorrermos a lei verificamos que o próprio legislador usa conceitos abstratos, v.g., "racial", "território de origem", ou mesmo quando usa conceitos como "serviços", "atividade económica", que muito embora possam ser lidos à luz dos instrumentos internacionais, europeus e mesmo internos, os mesmos abarcam um sem fim de situações que urgem ser delimitadas atentas preocupações de segurança jurídica que tem de ser assegurada pelo próprio texto legal ${ }^{45}$. Por isso mesmo, apesar de ser certo que toda a definição é em si "perigosa" 46 , somos do entendimento que tais conceitos indeterminados poderiam encontrar um mínimo de densificação legal ao lado de conceitos como discriminação direta, indireta, por associação, múltipla ou assédio ${ }^{47}$.

Por outro lado, este regime jurídico, como já apontava o Relatório da Comissão Europeia contra o Racismo e Intolerância (ECRI) ${ }^{48}$, deveria incluir também as características protegidas da religião e da língua ${ }^{49}$, que em nosso entendimento deveriam figurar e ser alvo de proteção da Lei n. ${ }^{0}$ 93/2017, de 23 de agosto.

Neste seguimento, chame-se à colação a dispersão institucional a que está votada esta matéria, isto é, a temática da não discriminação está hoje atribuída a várias entidades diferentes, e nem todas têm o poder de aplicar sanções pela efetiva violação do direito protegido $^{50}$.

45 Gomes Canotilho e Vital Moreira densificam estes conceitos, atribuindo a "raça" o significado de "grupos de pessoas com determinadas características (reais ou imaginárias) ou a "território de origem", a "Pátria", o "País" ou o "povo" em que nasceram as pessoas. Ob. cit. nota de rodapé 31, p. 342.

46 Do brocardo latino "omnia definitio periculosa est".

47 Nem sempre situações que possam traduzir-se em práticas discriminatórias na forma de assédio, poderão constituir contraordenação uma vez que a diferença entre estas e o ilícito criminal é ténue.

48 ECRI - Relatório sobre Portugal (quinto ciclo de controlo). [Consultado em: 15 de Janeiro de 2019]. Disponível em: https://rm.coe.int/fifth-report-on-portugal-portuguese-translation-/16808de7db, p. 14 e ss.

49 Aliás o Relatório da ECRI vai mais longe, ao propor o acolhimento das características da orientação sexual e da identidade de género.

50 Falamos aqui de entidades como por exemplo a Comissão para a Liberdade Religiosa que não tem competências sancionatórias nos termos da Lei n. ${ }^{\circ} 16 / 2001$, de 22 de junho, que institui a Lei da Liberdade Religiosa. 
No entorno laboral, situações de alegadas práticas discriminatórias em razão étnico-racial, estão atribuídas à Autoridade para as Condições no Trabalho ${ }^{51}$; as situações ocorridas nos media digitais e não digitais está atribuída à Entidade Reguladora da Comunicação ${ }^{52}$; as situações emergentes no desporto estão debaixo da competência da recente criada Autoridade para a Prevenção e o Combate à Violência no Desporto ${ }^{53}$.

Tal repartição acentuada de competências forma assim aquilo que se pode chamar de minifúndio legal, através da criação de competências sobrepostas que não só poderiam, como deveriam estar na alçada de uma mesma entidade com a autoridade transversal de prevenção, proibição e combate da discriminação nas suas múltiplas e abrangentes formas.

O que, cremos, só se lograria com a criação de uma entidade independente, desligada do aparelho, pelo que, "as autoridades deveriam transformar a CICDR numa entidade jurídica distinta, colocada fora do executivo e do poder legislativo, assegurar a sua independência de jure e de facto (...), como bem aponta o Relatório da ECRI ${ }^{54}$.

Uma outra crítica que poderá ser tecida a este regime jurídico é a aplicação, do ilícito de mera ordenação social previsto no Decreto-Lei n. ${ }^{\circ}$ 233/82, de 27 de outubro como regime supletivo. Sem porém deixar de reconhecer que, tratando-se de um regime contraordenacional, haverá sempre de haver um referente geral onde tal regime se locuplete, a verdade é

51 A matéria da igualdade e não discriminação na área laboral encontra-se prevista no artigo $24 .^{\circ}$ da Lei 7/2009, de 12 de fevereiro que institui que "o trabalhador ou candidato a emprego tem direito a igualdade de oportunidades $e$ de tratamento no que se refere ao acesso ao emprego, à formação e promoção ou carreira profissionais e às condições de trabalho, não podendo ser privilegiado, beneficiado, prejudicado, privado de qualquer direito ou isento de qualquer dever em razão, nomeadamente, de ascendência, idade, sexo, orientação sexual, identidade de género, estado civil, situação familiar, situação económica, instrução, origem ou condição social, património genético, capacidade de trabalho reduzida, deficiência, doença crónica, nacionalidade, origem étnica ou raça, território de origem, língua, religião, convicções políticas ou ideológicas e filiação sindical, devendo o Estado promover a igualdade de acesso a tais direitos." A Autoridade para as Condições no Trabalho, é a entidade a quem compete, nos termos do artigo $2 .^{\circ}$, n. $^{\circ}$ 2, al. k) do Decreto Regulamentar n. ${ }^{\circ} 47 / 2012$, de 31 de julho, assegurar o prosseguimento das contraordenações laborais.

52 A ERC, é uma entidade administrativa independente que exerce poderes de regulação e supervisão do respetivo setor conforme prevê o artigo $1 .^{\circ}$, n. ${ }^{\circ} 1$ da Lei n. ${ }^{\circ}$ 53/2005, de 8 de novembro, designadamente de todas as entidades que prossigam atividades de comunicação social tais como: agências noticiosas, operadores de rádio e televisão, entre outras. Encontram-se sujeitas à supervisão e intervenção do Conselho Regulador da ERC, todas as entidades que prossigam atividades de comunicação social designadamente "os operadores de rádio e de televisão relativamente aos serviços de programas que difundam ou aos conteúdos complementares que forneçam, sob sua responsabilidade editorial, por qualquer meio, incluindo por via eletrónica", artigo $6 .^{\circ}$, al. ${ }^{\circ} \mathrm{c}$ ) da Lei n. ${ }^{\circ} 53 / 2005$, de 8 de novembro. Constituem atribuições da ERC, de entre outras, "garantir o respeito pelos direitos, liberdades e garantias" (artigo $8 .^{\circ}$, al. d) da Lei n. ${ }^{\circ}$ 53/2005, de 8 de novembro).

53 Nos termos do artigo $14 .^{\circ}$ do Decreto-Lei n. ${ }^{\circ}$ 93/2014, de 23 de junho, é competente para fiscalizar o cumprimento das regras legais de organização e funcionamento das federações desportivas, a organização da Administração Pública com competência na área desportiva. Atendendo à missão que se encontra atribuída ao IPDJ, I.P., prevista no artigo $4 .^{\circ}$ do Decreto-Lei n. ${ }^{\circ}$ 98/2011, de 21 de setembro, designadamente na área do desporto e juventude. $\mathrm{O}$ IPDJ, I.P., tem ainda, em específico, a missão de aplicar e fiscalizar o cumprimento das leis aplicáveis no seu âmbito de atuação, podendo propor e aplicar medidas preventivas e repressivas no âmbito da ética do desporto, designadamente no tocante ao racismo e xenofobia no desporto.

54 Relatório da ECRI sobre Portugal...p. 17. 
que o ilícito de mera ordenação social não oferece, por vezes, soluções satisfatórias, quando está em causa um processo contraordenacional com vítimas concretas e determinadas ${ }^{55}$.

É por outro lado imperioso constatar a necessidade urgente de regulamentar a Lei n. ${ }^{\circ} 93 / 2017$, de 23 de agosto, prevendo-se com maior grau de detalhe os trâmites legais aplicáveis e assim tornar a tarefa do aplicador mais rigorosa e clara. Donde, há que reconhecer que matérias como o regime sancionatório da lei na parte da tramitação contraordenacional pura ou o regime da mediação carecem de melhor configuração legal.

Apesar do grandioso esforço por parte das instituições estatais, nomeadamente o ACM, I.P., na promoção e prevenção da discriminação racial e de dar a conhecer os instrumentos legais existentes ${ }^{56}$, a verdade é que os mecanismos previstos pela Lei n. ${ }^{\circ}$ 93/2017 ainda são desconhecidos do público em geral, o que pode contribuir para que casos de efetiva violação de direitos com base na distinção étnica e racial seja desconhecida das instâncias formais de controlo.

\section{B. A tutela criminal - $O$ artigo $240 .^{\circ}$ do Código Penal}

Do lado da tutela criminal, encontra-se plasmado no Código Penal português, no artigo $240 .^{\circ}$, o crime de discriminação e incitamento ao ódio e à violência, recentemente alterado pela Lei n. ${ }^{0}$ 94/2017, de 23 de agosto $^{57}$.

O bem jurídico que se visa tutelar neste tipo legal de crime é a igualdade entre todos os cidadãos do mundo. À semelhança da Lei n. ${ }^{\circ}$ 93/2017, a criação deste ilícito criminal decorre também da Convenção Internacional Sobre a Eliminação de Todas as Formas de Discriminação Racial ${ }^{58}$, introduzida no sistema punitivo português pela Lei n. ${ }^{0}$ 7/82, 29 de abril que aprovou a adesão àquela convenção.

Diferentemente daquilo que se acha plasmado na Lei n. ${ }^{\circ}$ 93/2017, de 23 de agosto, que prevê um elenco de práticas discriminatórias passíveis de constituir contraordenação, e que por isso, apenas admitem a coima como sanção principal, o crime de discriminação

55 Apesar de este ser um tema vasto, que nesta sede não pretendemos dar enfoque, a verdade é que para além do Decreto-Lei n. ${ }^{\circ}$ 233/82, de 27 de outubro ser um diploma desajustado para os dias que correm, a verdade é que a sua aplicação supletiva no regime da prevenção e proibição da discriminação racial se mostra duplamente desajustado. Refira-se a este propósito o leque de sanções acessórias previstas para este último regime (artigo 21. ${ }^{\circ}$ do Decreto-Lei n. ${ }^{\circ} 233 / 82$ ).

56 Falamos aqui de ações informativas e campanhas de sensibilização, das quais se destacam as ações de formação junto de entidades públicas, como se pode constatar no Relatório Anual da CIDR, 2017, p. 27 e ss.

57 Este tipo legal de crime foi alterado no mesmo dia da publicação do regime jurídico do combate à discriminação racial, Lei n. ${ }^{\circ}$ 93/2017, de 23 de agosto.

58 Ao assinarem esta Convenção "os Estados partes condenam a propaganda e as organizações que se inspiram em ideias ou teorias fundadas na superioridade de uma raça ou de um grupo de pessoas de uma certa cor ou de uma certa origem étnica ou que pretendem justificar ou encorajar qualquer forma de ódio ou de discriminação

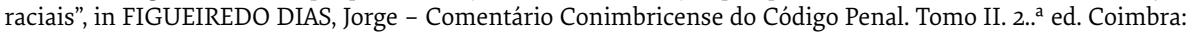
Almedina, 2012, p. 576. 
e incitamento ao ódio convoca um modus operandi próprio (punível com pena de prisão como pena principal) que implica o desenvolvimento de uma conduta que MARIA JoÃo ANTUNES ${ }^{59}$ classifica em três modalidades distintas: a fundação, constituição ou participação em organizações que incitem ao ódio racial; o desenvolvimento ou a participação em atividades de propaganda organizada e a prestação de assistência a tais organizações, incluindo o seu financiamento.

Digamos que mais do que sancionar práticas discriminatórias com base na raça, cor, nacionalidade ou território de origem, do que se trata nesta sede é de combater grupos ou estruturas organizadas que promovam ou disseminem a apologia ao ódio racial.

Por outro lado, algo que já estava previsto antes de 2017, era a punição, por via do seu n. ${ }^{\circ} 2$, da divulgação pública de escritos que difundissem por via da comunicação social, a violência, a difamação, a injúria ou a ameaça.

Na nossa opinião, bem andou o legislador neste particular, ao inserir subtipos legais de crime dentro deste tipo geral. De facto, a criminalização destes comportamentos vem dar resposta ao que tem sido a tendência criminógena de base étnico-racial e de incitamento ao ódio que se vem banalizando um pouco por toda a parte.

Não é por acaso que a Lei n. ${ }^{\circ}$ 96/2017, de 23 de agosto que define os objetivos, prioridades e orientações de política criminal 2017-2019, à qual já nos debruçámos supra ${ }^{60}$, previu, como crimes de prevenção prioritária, tendo em conta a dignidade dos bens jurídicos tutelados e a necessidade de proteger as potenciais vítimas, os crimes motivados por discriminação racial.

A onda securitária de que vimos falando, motivada pelas transformações operadas pela deslocação de migrantes em massa, o alastramento de um clima de insegurança intensificado pelos ataques terroristas dos últimos anos, aliada a pré-conceitos enraizados de forma mais ou menos ostensiva na sociedade hodierna, faz com que proliferem de forma alucinante novos discursos de ódio exclusiva ou quase exclusivamente tecidos nas plataformas digitais.

Os comportamentos desviantes, sustento destas novas vias germinadoras do crime, constitui uma das ameaças dos tempos modernos, fenómenos nem sempre ainda a coberto de uma tutela que se quer eficaz e rápida.

Os casos subsumíveis no artigo 240 ${ }^{\circ}$ do Código Penal não são exceção. Apesar da multiplicação desta nova forma de delinquir a verdade é que, por um lado, são ainda reduzidos os casos que chegam ao conhecimento das autoridades, e, mesmo os que chegam representam

59 FIGUEIREDO DIAS, Jorge - Comentário Conimbricense..., p. 576.

60 Vide p. 7. 
cerca de 0,01\% do total de crimes registados ${ }^{61}$. Em 2016, segundo dados da Direção-Geral da Política de Justiça, não existiam ainda processos findos referentes ao crime de discriminação racial.

Ora daqui deflui a necessidade de recentrar esta questão. Será uma questão puramente legal? Será uma questão de aplicação? Ou estará em causa uma deficitária preparação ou falha de formação das magistraturas?

Neste ponto, que se quer de viragem, cremos estarem em causa algumas deficiências. Enumeremos apenas algumas.

O cerne da questão não está na lei em si ou na falta de tutela penal para casos de efetiva discriminação racial. O que está em causa, cremos, poderá ser uma lacuna ao nível da formação das magistraturas ou dos órgãos de polícia criminal, estes últimos que lidam em primeira linha com situações de efetiva infração penal.

Por outro lado, há que reconhecer que um aprofundamento da temática, tanto com contributos doutrinários, que se começam a sentir na colaboração institucional entre entidades ou mesmo no encaminhamento de situações que consubstanciem ilícitos criminais pelas entidades administrativas - como a CICDR - à autoridade judiciária competente para posterior investigação dos factos, faz com que o enquadramento técnico-jurídico das situações potenciadoras de discriminação saia reforçado e aprimorado.

É necessário pois que se opere esta partilha intrainstitucional, uma vez que a mesma possibilitará um reforço dos bens jurídicos a tutelar, quando se fala de discurso de ódio.

Não se olvide por outro lado que a própria lei oferece subterfúgios da deriva qualificadora ao próprio aplicador do direito. Vejamos a linha entre a qualificação jurídico-abstrata de um crime qualificado no artigo $240 .^{\circ},{ }^{\circ}{ }^{\circ}$, alínea b) do $\mathrm{CP}$ - crime de difamação ou injúria de pessoas com base na sua raça - que representa um vasto número de situações ocorridos na internet ou media sociais, ou no artigo $181 .^{\circ}$ do $\mathrm{CP}$ - crime de injúria - apesar de parecer ténue, não o é.

Enquanto que no primeiro caso se trata de um crime de natureza pública em que a moldura penal se situa entre os 6 meses e os 5 anos, no segundo caso, o crime tem natureza particular e é punido com pena de prisão até 3 meses ou com pena de multa até 120 dias ${ }^{62}$.

61 CICDR - Relatório Anual 2017..., p. 41. De acordo com os dados fornecidos pela Direção-Geral da Política de Justiça (DGPJ) em 2017, do total de 330.872 crimes registados pelas autoridades policiais, apenas 25 diziam respeito a crimes de discriminação racial ou religiosa. Destes, a grande maioria ocorreu no distrito de Lisboa (14), seguido do Porto (3), e Setúbal (3), sendo os restantes distribuídos pelos distritos restantes.

62 Pode acontecer que dadas as circunstâncias factuais apresentadas na queixa ou na denúncia seja feito um enquadramento no crime de injúria do artigo $181 .^{\circ}$ e não no crime de discriminação e incitamento ao ódio e à violência. 
As diferenças são arreigadas e a inserção em um ou em outro pode minar a procedibilidade do processo e colocar a vítima do crime numa posição de desvantagem ${ }^{63}$.

Ambas as realidades têm por seu turno uma natureza diferente, sendo protegidos bens jurídicos diferentes. Enquanto que, como já tivemos oportunidade de realçar, com o crime de discriminação e incitamento ao ódio e à violência, o bem jurídico visado é a igualdade entre todos os cidadãos do mundo, com o crime de injúria visa-se proteger a honra e a consideração de uma determinada pessoa (porque visa uma pessoa concreta e determinada).

Entende-se por isso que os tipos de crime elencados no $n .^{\circ} 2$ do artigo $240 .^{\circ}$ do $\mathrm{CP}$ deverão manter o seu caráter público, embora isoladamente o não sejam, sendo de evitar que casos deste jaez sejam qualificados pelas autoridades judiciárias nos tipos isolados - injúria, difamação, ameaça, etc - o que poderá acarretar a falência do processo ab initio.

\section{Conclusões - notas finais}

Aqui chegados, afigura-se estabelecer um ponto de chegada. E, consequentemente um ponto de partida.

A realidade em que nos movimentamos, o rumo dos acontecimentos que temos presenciado e vivenciado clama por respostas no sentido de preservar princípios universais básicos que pretendem salvaguardar o bem supremo da dignidade da pessoa humana.

Ao ritmo conturbado e perturbado com que se deteriorou a relação entre os seres humanos, mor da instabilidade fomentada por conflitos armados, que pressionam as movimentações migratórias, mas também um certo aguçamento de perceções preconceituosas reforçadas por este clima, fizeram com que fosse despoletado e incitado o ódio racial, fomentando um clima de intolerância generalizada.

Para contrariar este modus essendi, os Estados, e, em particular Portugal, têm acolhido nas suas legislações internas mecanismos de tutela a fim de debelar a disseminação de situações potenciadoras de discriminação racial. No caso português vimos como, a vários níveis, essa tutela se mostra plasmada na lei, tanto de um ponto de vista administrativo quanto criminal.

Se algumas críticas podem ser assacadas em ambos os regimes, o que cremos, ainda que esparsamente ter apontado, a questão posiciona-se, em nossa opinião no distanciamento que existe entre a previsão legal de mecanismos de proteção e a efetiva aplicação dos mes-

63 A verdade é que, se a apreciação do Ministério Público for a de que em abstrato está em causa um crime de injúria, o ofendido tem de apresentar queixa, constituir-se assistente - o que implica o pagamento de uma taxa de justiça de duas UC's (abreviatura para "unidade de conta"), isto é, 200€, e deduzir acusação particular (como decorre do artigo $50 .^{\circ}$ do Código de Processo Penal) 
mos. Óbices de natureza procedimental são, em larga medida os causadores de eventual não procedibilidade do processo em si, mas também há que reconhecer que é necessário dotar os aplicadores do direito de conhecimentos específicos para lidar com casos de discriminação racial.

Cientes de que esta pequena incursão na temática se fica aquém daquilo a que a mesma obriga, julgamos ter dado uma visão dos meios tutelares existentes no ordenamento jurídico interno que visam proteger a não discriminação assente na origem racial e étnica, cor, nacionalidade, ascendência e território de origem, aventando algumas soluções que constituem o nosso ponto de partida. Para que pontos de chegada sejam construídos e plenamente alcançados.

\section{REFERÊNCIAS BIBLIOGRÁFICAS}

BRANDÃO, Ana Paula - O nexo interno-externo na narrativa securitária da União Europeia. In Janus.Net e-journal of International Relations. Lisboa. e-ISSN 1647-7251. V. 6, N. ${ }^{\circ}$ 1, 2015, p. 1-20.

CANOTILHO, J.J. Gomes; MOREIRA, Vital - Constituição Anotada. Volume I, 4.. ${ }^{\text {a }}$ ed. rev. Coimbra: Coimbra Editora, 2007.

CICDR - Relatório Anual 2017: Igualdade e Não Discriminação em razão da Origem Racial e Étnica, Cor, Nacionalidade, Ascendência e Território de Origem. [Consultado em: 16 de Janeiro de 2019]. Disponível em: https://www.cicdr.pt/-/relatorio-anual-sobre-a-situacao-da-igualdade-e-nao-discriminacao-racial-e-etnica

DIÁRIO DE NOTÍCIAS - Dinamarca quer isolar migrantes "indesejados" numa ilha. [Consultado em: 15.01.2019]. Disponível em: https://www.dn.pt/mundo/interior/dinamarca-quer-isolar-migrantes-indesejados-numa-ilha-10274361.html

ECRI - Relatório sobre Portugal (quinto ciclo de controlo). [Consultado em: 15 de Janeiro de 2019]. Disponível em: https://rm.coe.int/fifth-report-on-portugal-portuguese-translation-/16808de7db

FIGUEIREDO DIAS, Jorge - Comentário Conimbricense do Código Penal. Tomo II. 2.. ${ }^{\mathrm{a}}$ ed. Coimbra: Almedina, 2012.

GIL, Ana Rita - Imigração e Direitos Humanos. Lisboa: Petrony, 2017.

IOM, UN MIGRATION - Mediterranean Update: Migration Flows Europe: Arrivals and Fatalities (31 January 2017). [Consultado em: 17 de Janeiro de 2019]. Disponível em: https://www.iom.int/infographics/ mediterranean-update-migration-flows-europe-arrivals-and-fatalities-31-january-2017

MIRANDA, Jorge - Manual de Direito Constitucional. Tomo II. 3.. ed., reimpr. Coimbra: Coimbra Editora, 1996.

MOURA, Patrícia de - A Finalidade Do Princípio Da Igualdade: A Nivelação Social: Interpretação Dos Atos de Igualar. Porto Alegre: Sérgio António Fabris, 2005.

OLIVEIRA REIS, Catarina (Coord.); GOMES, Natália - Indicadores de Integração de Imigrantes: Relatório Estatístico Anual. Lisboa: Alto Comissariado para as Migrações, 2018.

OLIVEIRA REIS, Catarina (Coord.); GOMES, Natália - Monitorizar a Integração de Imigrantes em Portugal: relatório estatístico decenal. Lisboa : Alto Comissariado para as Migrações, 2014. 
PADILLA, Beatriz; ORTIZ, Alejandra - Fluxos Migratórios em Portugal: Do Boom Migratório à desaceleração no contexto de crise. Balanços e desafios. In Revista Interdisciplinar da Mobilidade Humana. Brasília. ISSN 1980-8585. N. ${ }^{\circ}$ 39, A. XX, 2012, p. 159-184.

UNIÃO EUROPEIA - Conselho da Europa. Recomendação 97(20), de 30.10.1997. "Recommendation of the Committee of Ministers to Member States on "Hate Speech". [Consultado em: 18 de Janeiro de 2019]. Disponível em: https://rm.coe.int/CoERMPublicCommonSearchServices/ DisplayDCTMContent?documentId=0900001680505d5b

VALENTE, Manuel Monteiro Guedes - Direito Penal do Inimigo e o Terrorismo. 2.. ${ }^{a}$ ed. Coimbra: Almedina, 2017. 